\title{
Rapid Visco Analyzer Measurements of japonica Rice Cultivars to Study Interrelationship between Pasting Properties and Farming System
}

\author{
Amit Kesarwani, ${ }^{1,2}$ Po Yuan Chiang, ${ }^{3}$ and Shih Shiung Chen ${ }^{4}$ \\ ${ }^{1}$ Department of Agronomy, College of Agriculture, G. B. Pant University of Agriculture and Technology, \\ Pantnagar, Uttarakhand 263145, India \\ ${ }^{2}$ Department of Agronomy, National Chung Hsing University, Taichung 40227, Taiwan \\ ${ }^{3}$ Department of Food Science and Technology, National Chung Hsing University, Taichung 40227, Taiwan \\ ${ }^{4}$ Department of Post Modern Agriculture, Ming Dao University, Changhua County 52345, Taiwan
}

Correspondence should be addressed to Amit Kesarwani; getkesar@gmail.com

Received 30 September 2015; Revised 19 January 2016; Accepted 26 January 2016

Academic Editor: Silvia Imhoff

Copyright (C) 2016 Amit Kesarwani et al. This is an open access article distributed under the Creative Commons Attribution License, which permits unrestricted use, distribution, and reproduction in any medium, provided the original work is properly cited.

Rheological properties influence the starch softness and cooking quality. Two japonica rice cultivars were studied that were cultivated under organic and conventional farming. Study was conducted for 2 years in popular japonica cultivars, that is, Kaohsiung number 139 and Taikeng number 16, which were grown twice a year in Taiwan. The results highlighted that major pasting properties such as peak viscosity, setback value, and pasting temperature improved under organic farming; however, in further analysis, eating and cooking quality reported no significant changes except aroma in rice.

\section{Introduction}

Starch is the major component of rice and described its physiochemical properties, such as gel strength and pasting properties [1-3]. The japonica cultivars are the major rice variety used for the preparation of important snacks and food materials in Asian countries. Most of the manufacturers prefer rice flour instead of starch for preparing processed products. However, the swelling and pasting properties of starch granule were influenced not only by starch solely but also by lipids, protein, and mineral compounds [1]. The starch granules of rice play active role; if there is less swelling of starch during gelatinization, the peak viscosity of starch paste will be lower [4]. To understand the viscosity properties of rice starch, the RVA works as a physical index for the estimation and as a precursor of cooking and processing qualities [2, 5-7]. Among the different RVA profiles, setback and breakdown values play significant role as compared to peak viscosity and others in the estimation of cooking quality of rice starch properties [6]. The characteristic of RVA is closely connected to taste quality of rice, where higher peak viscosity and breakdown and the smaller setback value enhance the grain quality. The rice cooked is soft and glutinous in texture [8].

The amount of amylose content in starch is positively correlated with rate and extent of retrogradation [9]. Study showed that cooked rice with higher amylose rice starch varieties had lesser stickiness, cooked dry, while, keeping higher setback values [10] or cultivars with lower breakdown value, peak viscosity and taste meter values fall in the category of inferior qualities rice variety [5].

The cause of alteration on rheological properties is mainly genotypic; however, environmental factors also play active role in description. Recent studies focused on the rice quality influenced with increase in fertilization level and cultivation method, but the results remain inconsistent and ambiguous. The ability to improve the eating quality of rice under organic practice is recent thrust under Asian background, and it has been found that, in the long term sustainable cultivation of rice for 16 years, the organic practice of rice cultivation [11] enhances the rice eating quality by consequently improving the starch viscosity (increases starch stickiness) as higher 
values of breakdown and maximum viscosity of brown rice flour. Also, continuous fertilization could improve the pasting properties of the rice starch except for setback, which is found on par at $50 \% \mathrm{~N}$ rate also [12]. Earlier studies also reported the inverse relationship between enhanced $\mathrm{N}$ fertilization in conventional farming and deterioration in cooking quality of rice $[5,12-17]$. There are few studies in which cooked rice eating quality has been related with protein content $[2,5,12$, $17,18]$ or secondary structures (amylose and amylopectin), where long chain amylopectin influenced negatively the breakdown viscosity, while amylose has positive correlation [19]. Thus, to understand the mechanism of chemical or organic fertilizer influence on rheological characteristics, the objective of this study is designed to compare the pasting properties of milled rice under conventional and organic farming.

\section{Materials and Methods}

2.1. Rice Sample Collection. Two commercial japonica rice cultivars, namely, medium and slender grain features (Taikeng-16 commonly known as TK-16) and short and round grain (Kaohsiung-139 commonly known as KSH-139), grown in Central Taiwan (Chiayi County) and Eastern Hualien County (Taiwan, ROC), respectively, were selected. These cultivars were cultivated twice a year in Taiwan as first crop (February to June) and second crop (August to November) during 2009-2011 [20]. All the products were labelled and certified [21] under Taiwan CAS agricultural product quality and Taiwan Formosa Organic Association (FOA). Rice cultivated under conventional farming used chemical fertilizers, pesticides, and recommended package of practice. Organic rice cultivars were strictly adhered to the cultivation practice given by Taiwan CAS and certification agency. Also, exclusion of any chemicals and only use of biodegradable inputs were allowed. Samples were well labelled without any physical or biological impurities and stored vacuum-packaged at room temperature until further analysis conducted.

2.2. General Chemical Analysis. Moisture, protein, ash, fat, and crude fiber were determined by American Association of Cereal Chemists approved methods [22]. Total carbohydrates content was estimated based on difference [23]. General details of mentioned physiochemical properties in both cultivars have been provided in Supplementary Material available online at http://dx.doi.org/10.1155/2016/3595326.

2.3. RVA Analysis of Rice. Milled rice sample for RVA analysis was ground with a grinder and sieved with 100-mesh screen. Three grams of the ground-milled rice was weighed (weight adjusted to $12 \%$ moisture basis) determined by AACC $44-$ 31A [24] and with $25 \mathrm{~mL}$ distilled water was blended. After blending, the rice-water slurry was transferred to the RVA (RVA-Ezi, Newport Scientific, Warriewood, NSW, Australia). The pasting properties of rice flour slurry were measured on dry weight (dw) basis. The RVA was set at $50^{\circ} \mathrm{C}$ as the starting temperature and held at the same temperature for $1.5 \mathrm{~min}$
TABLE 1: Detail of RVA analysis cycle of rice.

\begin{tabular}{lcc}
\hline Time (HH:MM:SS) & Type (temp/speed) & Value $\left({ }^{\circ} \mathrm{C}\right)$ or rpm \\
\hline 00:00:00 & Temp & 50 \\
00:00:00 & Speed & 480 \\
00:00:01 & Speed & 960 \\
00:00:10 & Speed & 160 \\
00:01:30 & Temp & 50 \\
00:05:15 & Temp & 95 \\
00:07:15 & Temp & 95 \\
00:11:00 & Temp & 50 \\
00:17:00 & temp & 50 \\
End of test time: 00:17:00 & Initial idle temp $\left({ }^{\circ} \mathrm{C}\right)=50$ \\
\hline
\end{tabular}

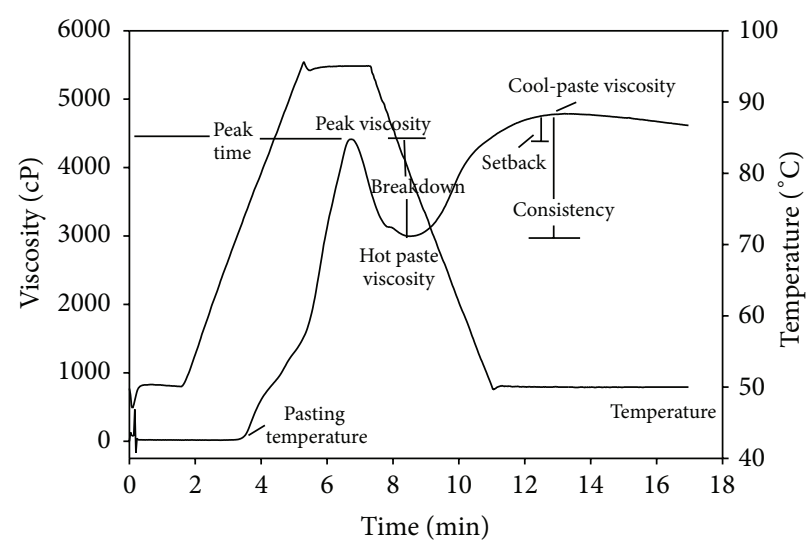

FigURE 1: RVA profiles of rice starches.

(Table 1). Lately, the slurry was heated to $95^{\circ} \mathrm{C}$ at the rate of $12^{\circ} \mathrm{C}$ per min while being maintained for $2 \mathrm{~min}$ at paste temperature. Then, temperature is brought down to $50^{\circ} \mathrm{C}$ with the decreasing rate of $12^{\circ} \mathrm{C}$ per min and kept for 6 min at same temperature. The total processing time was about $17 \mathrm{~min}$. The paste viscosity properties of the rice examined were peak viscosity $(\mathrm{P})$ (maximum viscosity between the heating and holding cycles), hot paste viscosity (HP) (minimum viscosity after peak), and cool-paste viscosity (CP) (the viscosity of the paste after cooling). All values were recorded in centipoise (cP). For detailed study, three derived viscosity values were also calculated as follows (Figure 1): breakdown viscosity (BD) (peak viscosity minus hot paste viscosity), setback viscosity (SB) (cool-paste viscosity minus peak viscosity), and consistency viscosity (CON) (cool-paste viscosity-hot paste viscosity). The pasting temperature (PT) and peak time $(\mathrm{PkT})$ were also recorded $[25,26]$. The measurements were in triplicate.

2.4. Statistical Analysis. From both farming practices, 5 samples with 3 replications were formulated for every parameter. Later, all data compilation were utilized for correlation estimation. The data were subjected to ANOVA using SAS version 8.1 (SAS Institute, Cary, NC) and expressed as means \pm standard errors of each factor. Duncan's Multiple Range Test was further used to determine significant differences between means and was considered statistically significant if $P \leq 0.05$. 
TABLE 2: F-values for amylographic characteristics $(\mathrm{cP})$ of rice cultivars influenced by agricultural practice in two crop seasons.

\begin{tabular}{|c|c|c|c|c|c|c|c|c|}
\hline Source & $\mathrm{PkT}$ & $\mathrm{PT}$ & $\mathrm{P}$ & $\mathrm{HP}$ & $\mathrm{BD}$ & $\mathrm{CP}$ & $\mathrm{CON}$ & SB \\
\hline Properties & $* * * *$ & $* * * *$ & $* * * *$ & $* * * *$ & $* * * *$ & $* * * *$ & $* * * *$ & $* * * *$ \\
\hline Season (S) & $* * * *$ & $* * * *$ & $* * * *$ & $* * * *$ & $* * * *$ & $* * * *$ & $* * * *$ & $* * * *$ \\
\hline Treatment $(\mathrm{T})$ & $* * * *$ & $* *$ & $* * * *$ & $* * * *$ & ns & $* * * *$ & $* * * *$ & $* *$ \\
\hline Cultivar (C) & $* * * *$ & $* * * *$ & $* * * *$ & $* * * *$ & $* * * *$ & $* * * *$ & ns & $* * * *$ \\
\hline $\mathrm{S} * \mathrm{~T}$ & $* * * *$ & $* * * *$ & $* * * *$ & $*$ & $* * * *$ & $* * * *$ & $* * * *$ & $* * * *$ \\
\hline $\mathrm{S} * \mathrm{C}$ & $* * * *$ & $* * * *$ & $* * * *$ & * & $* * * *$ & $* * * *$ & $* * * *$ & $* * * *$ \\
\hline $\mathrm{T} * \mathrm{C}$ & $* * * *$ & $* * * *$ & $* * * *$ & $*$ & $* * * *$ & $* * * *$ & $* * * *$ & $* * * *$ \\
\hline $\mathrm{S} * \mathrm{~T} * \mathrm{C}$ & $* * * *$ & $* *$ & $* * * *$ & $* *$ & $* * * *$ & $*$ & $* * * *$ & $* * * *$ \\
\hline
\end{tabular}

PkT: peak time; PT: pasting temperature; P: peak viscosity; HP: hot paste viscosity; BD: breakdown viscosity (P-HP); CP: cool-paste viscosity; CON: consistency viscosity $(\mathrm{CP}-\mathrm{HP})$; SB: setback viscosity $(\mathrm{CP}-\mathrm{P})$; ns: values statistically nonsignificant $(P>0.05)$.

$*=P \leq 0.05 ; * *=P \leq 0.01 ; * * * *=P \leq 0.0001$.

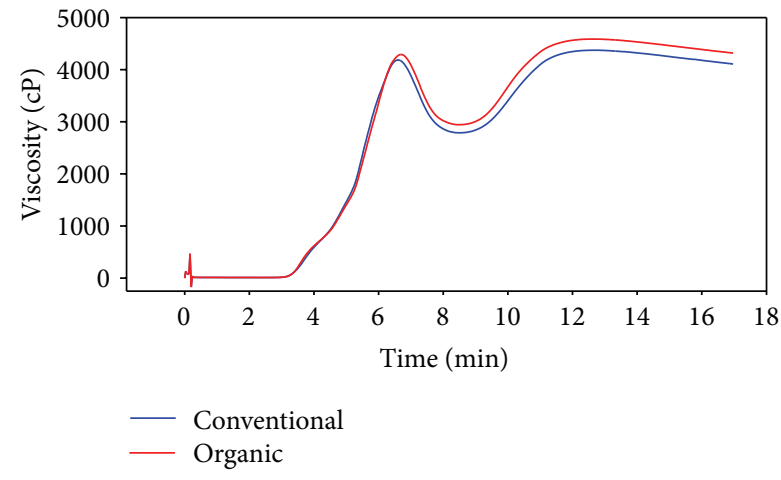

(a)

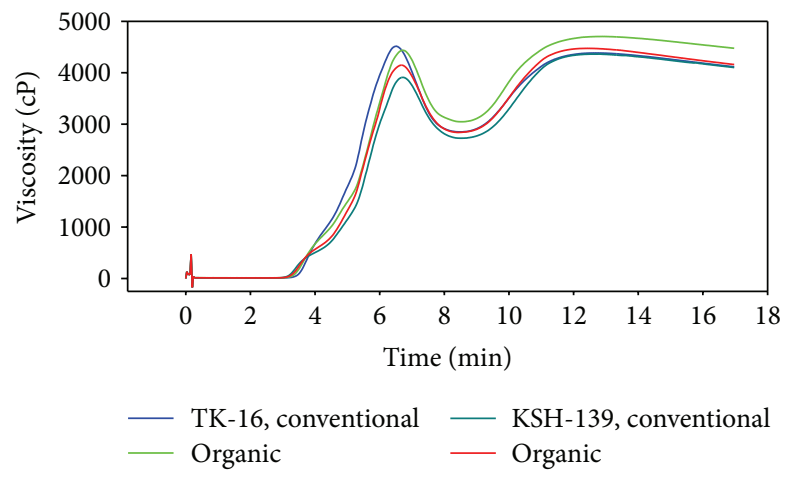

(b)

FIGURE 2: RVA profiles of rice cultivars compared according to (a) farming practices and (b) varietal differences.

\section{Results and Discussions}

RVA breakdown is caused by disruption of the gelatinized starch granule structure [27]. Thus, the extent of breakdown is caused by the difference between the viscosity when swollen, gelatinized starch granules existed and the viscosity when the gelatinized starch granules are disrupted, either partially or completely [19]. The cooking behavior of starches and the viscosity of the resulting pastes can be studied with an instrument called Rapid Visco Analyzer (RVA). The RVA profile is generally used as one of the indirect indicators for eating quality in rice sensory evaluation. Viscosities at the start of the holding period and during cooling reflect the ease of cooking starch and paste stability, respectively. Each viscosity is used to identify a particular characteristic of the rice variety.

Basically the starch retrogradation relatively controlled the increase in paste viscosity [28], whereas shear and rupturing of swollen starch granules are regulated by breakdown viscosity. Setback viscosity implies the degree of retrogradation. The study showed that usually amylographic properties are significantly influenced by abiotic factors (Table 2) (except breakdown and consistence viscosity). Also, the cultivars responded differently $(P \leq 0.05)$ in each season cultivated under different farming (Figure 2 ).
The cultivars response was influenced by seasonal changes while cultivating under organic and conventional farming. It was estimated that second crop (S2, S4) had higher pasting properties as compared to first crop (data not shown). Similarly, it was also clear that pasting properties were significantly higher in organic farming, where second crop (S2) organic rice had much influence on pasting properties (Table 3$)$ except pasting temperature $(P \leq 0.05)$. Tamaki et al. [11] also favoured increase in peak viscosity and breakdown value due to continuous organic farming.

The inconsistent results prevail in sustainability of amylographic characteristics under studied cultivars when grown in various agronomic practices. The organically grown cultivars TK-16 and KSH-139 resulted in lower RVA values (except peak viscosity in TK-16 and peak time and pasting temperatures of $\mathrm{KSH}-139$, resp.).

Increase in protein content due to higher fertilization with $\mathrm{N}$ nutrition only increases the water-insoluble storage proteins but reduces the proportion of cysteine (disulphide bonding compound). The disproportionate ratio of disulphide bond and insoluble protein could ultimately reduce the viscosity. Moreover, the increasing level of protein thickened the wall around starch, which probably reduced the rate of pasting [2]. These specific protein natures (oryzenin, in case of rice) encircle the starch molecule to avoid the breakdown 
TABLE 3: Amylographic characteristics (cP) of rice cultivars as affected by treatments (conventional or organic).

\begin{tabular}{lcc}
\hline \multirow{2}{*}{ Properties } & \multicolumn{2}{c}{ Treatment } \\
\hline PkT $(\min )$ & Organic & Conventional \\
PT $\left({ }^{\circ} \mathrm{C}\right)$ & $71.6 \mathrm{a}$ & $6.6 \mathrm{~b}$ \\
P & $4382 \mathrm{a}$ & $71.8 \mathrm{a}$ \\
$\mathrm{HP}$ & $2939 \mathrm{a}$ & $4249 \mathrm{~b}$ \\
$\mathrm{BD}$ & $1443 \mathrm{a}$ & $2784 \mathrm{~b}$ \\
$\mathrm{CP}$ & $4318 \mathrm{a}$ & $1465 \mathrm{a}$ \\
$\mathrm{CON}$ & $1380 \mathrm{a}$ & $4109 \mathrm{~b}$ \\
SB & $-63 \mathrm{a}$ & $1325 \mathrm{~b}$ \\
\hline
\end{tabular}

PkT: peak time; PT: pasting temperature; P: peak viscosity; HP: hot paste viscosity; $\mathrm{BD}$ : breakdown viscosity (P-HP); CP: cool-paste viscosity; CON: consistency viscosity (CP-HP); SB: setback viscosity (CP-P). Values for each parameter followed by a different letter within each row are significantly different, $P \leq 0.05$ (Duncan's Multiple Range Test).

under high shear stress to enhance the swelling process further; however, it restricted the swelling in gelatinization process of starch granule under low shear stage [3]. The different level of fertilization significantly affects the rice quality and increases the protein content, while decreasing the peak, trough, and final viscosity in rice $[2,29]$. Also, rice varieties with different qualities had also difference in the rate and amount of nitrogen accumulation [5]. Other findings show that the differences in pasting properties and textural properties of cooked rice were due to difference in protein content compared to rice being grown under different fertility management [12].

Another concept also suggested that it might be attributed to balanced $\mathrm{Mg} / \mathrm{K}$ ratio as a suitable index of cooking properties with significant correlation with pasting properties [11]. Likewise, in a long term cultivation of rice, Bryant et al. [7] recorded decrease in peak and final paste viscosities in fertilization through chemicals in rice; however, no differences of Rapid Visco Analyzer profile were noticed in various rice crop rotations. Earlier further conformity of above findings was also reported as reduced peak [12], breakdown viscosity [14], and increment of setback viscosity [15] in the effect of enhanced $\mathrm{N}$ fertilization. The cooked rice of upland rice tends to be soft and sticky when the level of $\mathrm{N}$ increases from lower to optimum amount, which implies the lower value of breakdown and setback viscosity [16]; however, the further dose would deteriorate the cooking quality of rice grains. The changes in protein concentration can influence the pasting properties of rice [2]. The protein contents of rice grain are negatively correlated with peak and breakdown viscosity but positively with setback values [12]. Despite the differences in protein content with no effect on RVA profile of rice cultivar, this might be attributed to other secondary structures of rice (amylose and amylopectin), where long chain amylopectin influenced negatively the breakdown viscosity, while amylose has positive correlation [19].

The above findings of variation in amylographic characteristics due to crop season or agronomic practice were consistent with Kuo et al. [30] who also reported that peak viscosity, pasting temperature, and other properties were affected by the growth season. The high variation in most of the characteristics in both cultivars suggests that the genetic effects are the important part of the total variation, while findings were paralleled to the work of Gravois and Webb [31] and Kuo et al. [30] that indicated that starch viscosity properties were controlled by single-locus genes with additive effects.

An inverse relationship was established in our study of cooked rice hardness in sensory evaluation and RVA setback values (Table 4 ). The results were counterpart of earlier agreements which provided positive correlation between hardness (Supplementary Material) and setback values [4, 32]. Negative interaction between two properties might be attributed to growing conditions and genotypic difference of cultivars. Significant higher protein content was reported in conventionally grown rice compared to organic rice which might also be attributed to overall hardness in conventional product, whereas high temperature during grain filling stage causes the low moisture content of rice that increases hardness of spring crop compared to fall season. Lower content of amylose in organic rice and higher springiness bring the soft starch of rice compared to conventional samples (Supplementary Material). Higher content of protein tends to produce less swelling of starch grain by forming a gel layer surrounding the grain and let it absorb less water for swelling, while comparatively enhancing the hardness. Contrary results of higher cohesiveness and hardness of conventionally grown rice were reported in earlier studies with better score for eating quality compared to organic rice [33]. Higher peak and setback viscosity were reported in organic rice while breakdown values were lower compared to conventional product. There was a negative correlation found between peak and setback values in relation to crude protein content $(-0.18$ and -0.03 , resp.) of rice (Table 4$)$, whereas there is positive correlation with breakdown values (0.26). But all the correlation values were highly nonsignificant and in contrary to findings of Champagne et al. [12]. Their results presented that protein content was in negative correlation with peak and breakdown values and in positive correlation with setback viscosity. Negative correlation was also found between protein content and hot paste viscosity $(-0.28)$, which was in findings similar to our earlier results.

The partial enhancement in RVA properties of rice cultivars grown under organic farming was further analyzed for sensory properties in our study. The study reflected no significant improvement in cooking and eating quality when cultivated organically [13]; also see Supplementary Material. It was clearly indicated that future analysis needs to be focused on diversified cultivar investigation. Also, physical and chemical properties need to be interlinked with the grown condition of rice in various seasons.

\section{Conclusion}

The pasting properties has been improved slightly under organic farming, where peak viscosity and setback value had direct correlation with starch hardness. The pasting temperature was significantly lower in organic rice which 
TABLE 4: Correlation coefficient $(r)$ among various physicochemical characteristics of rice grain.

\begin{tabular}{lcccccc}
\hline \multirow{2}{*}{ Factors } & \multicolumn{4}{c}{ Correlation coefficient $(r)$} \\
& $\mathrm{P}$ & $\mathrm{HP}$ & $\mathrm{BD}$ & $\mathrm{CP}$ & $\mathrm{CON}$ & \multicolumn{1}{c}{$\mathrm{SB}$} \\
\hline Amylose & $0.06(\mathrm{~ns})$ & $-0.25(\mathrm{~ns})$ & $-0.08(\mathrm{~ns})$ & $-0.16(\mathrm{~ns})$ & $-0.02(\mathrm{~ns})$ & $-0.08(\mathrm{~ns})$ \\
Crude protein & $-0.18(\mathrm{~ns})$ & $-0.28^{*}$ & $0.26(\mathrm{~ns})$ & $0.17(\mathrm{~ns})$ & $0.38^{* *}$ & $-0.26(\mathrm{~ns})$ \\
\hline
\end{tabular}

P: peak viscosity; HP: hot paste viscosity; BD: breakdown viscosity (P-HP); CP: cool-paste viscosity; CON: consistency viscosity (CP-HP); SB: setback viscosity (CP-P); ns: values statistically nonsignificant $(P>0.05)$. Values are significant difference if $*=P \leq 0.05$ (significant); $* *=P \leq 0.01$ (highly significant).

causes granulation and swelling of amylopectin at earlier stage. The improved starch property was noticed under Taikeng number 16 cultivar when grown under organic practice; however, improvement in eating and cooking quality remains negligible variant due to changes in farming strategy (nonsignificant). Multivariate analysis needs to be conducted using photoinsensitive rice genotypes during cultivation [18].

\section{Conflict of Interests}

The authors declare that there is no conflict of interests regarding the publication of this paper.

\section{Acknowledgments}

This work was supported by the Association of Taiwan Organic Agriculture Promotion (ATOAP) organization, as a doctoral fund to Amit Kesarwani. Appreciation is expressed to Professor Po Yuan Chiang, Department of Food Science and Technology in Taichung, for their analytical assistance. The authors are also grateful to Professor Shih Shiung Chen for their valuable suggestions in project.

\section{References}

[1] V. Singh, H. Okadome, H. Toyoshima, S. Isobe, and K. Ohtsubo, "Thermal and physicochemical properties of rice grain, flour and starch," Journal of Agricultural and Food Chemistry, vol. 48, no. 7, pp. 2639-2647, 2000.

[2] M. Martin and M. A. Fitzgerald, "Proteins in rice grains influence cooking properties!" Journal of Cereal Science, vol. 36, no. 3, pp. 285-294, 2002.

[3] V. Derycke, W. S. Veraverbeke, G. E. Vandeputte, W. De Man, R. C. Hoseney, and J. A. Delcour, "Impact of proteins on pasting and cooking properties of nonparboiled and parboiled rice," Cereal Chemistry, vol. 82, no. 4, pp. 468-474, 2005.

[4] K. Tananuwong and Y. Malila, "Changes in physicochemical properties of organic hulled rice during storage under different conditions," Food Chemistry, vol. 125, no. 1, pp. 179-185, 2011.

[5] J. Jin, D. Y. Xu, Y. X. Cai et al., "Effect of N-fertilizer on main quality characters of rice and RVA profile parameters," Acta Agronomica Sinica, vol. 30, no. 2, pp. 154-158, 2004 (Chinese).

[6] J. Bao, S. Shen, M. Sun, and H. Corke, "Analysis of genotypic diversity in the starch physicochemical properties of nonwaxy rice: apparent amylose content, pasting viscosity and gel texture," Starch, vol. 58, no. 6, pp. 259-267, 2006.

[7] R. J. Bryant, M. Anders, and A. McClung, "Impact of production practices on physicochemical properties of rice grain quality," Journal of the Science of Food and Agriculture, vol. 92, no. 3, pp. 564-569, 2012.
[8] S. P. Liu, X. T. Nie, Q. G. Dai, Z. Y. Huo, and K. Xu, "Effect of interplanting with zero tillage and straw manure on rice growth and rice quality," Rice Science, vol. 14, no. 3, pp. 204-210, 2007.

[9] J. J. M. Swinkels, Industrial Starch Chemistry, AVEBE Brochure, Foxhol, The Netherlands, 1998.

[10] H. Kurasawa, Y. Kanauti, K. Takei et al., "Correlation analysis between eating quality, rheological property and amylose content of starch," Agricultural and Biological Chemistry, vol. 36, no. 10, pp. 1809-1813, 1972.

[11] M. Tamaki, K. Yoshimatsu, and T. Horino, "Relationships between the duration of organic farming culture and amylographic characteristics and mineral contents of rice," Japanese Journal of Crop Science, vol. 64, no. 4, pp. 677-681, 1995.

[12] E. T. Champagne, K. L. Bett-Garber, C. C. Grimm, and A. M. McClung, "Effects of organic fertility management on physicochemical properties and sensory quality of diverse rice cultivars," Cereal Chemistry, vol. 84, no. 4, pp. 320-327, 2007.

[13] A. Kesarwani, M. Sharma, S. K. Vaid, and S. S. Chen, "Impact of production practices on organoleptic intensity scale of different rice cultivars," Journal of Pharmacy and Nutrition Sciences, vol. 5, no. 2, pp. 114-120, 2015.

[14] S. S. Kesarwani, J. F. Chen, and J. F. Lee, "Determination of physicochemical properties of rice under organic farming in Taiwan," Environment and Ecology, vol. 32, no. 4, pp. 1445-1449, 2014.

[15] J. Sun, Y.-F. Chu, X. Wu, and R. H. Liu, "Antioxidant and antiproliferative activities of common fruits," Journal of Agricultural and Food Chemistry, vol. 50, no. 25, pp. 7449-7454, 2002.

[16] Q. B. Ye, H. C. Zhang, H. Li et al., "Effects of amount of nitrogen applied and planting density on RVA profile characteristic of Japonica rice," Acta Agronomica Sinica, vol. 31, no. 1, pp. 124130, 2005 (Chinese).

[17] Y.-J. Zhang, Y.-Y. Chen, G.-J. Yan, B. Du, Y.-R. Zhou, and J.-C. Yang, "Effects of nitrogen nutrition on grain quality in upland rice Zhonghan 3 and paddy rice Yangjing 9538 under different cultivation methods," Acta Agronomica Sinica, vol. 35, no. 10, pp. 1866-1874, 2009.

[18] M. Xu, D. Y. Wang, G. S. Shao, and X. F. Zhang, "Effects of transplanting density and nitrogen fertilizer rate on yield formation and grain quality of super high yielding rice Zhongzao 22," Chinese Journal of Rice Science, vol. 22, no. 5, pp. 507-512, 2008 (Chinese with English abstract).

[19] X.-Z. Han and B. R. Hamaker, "Amylopectin fine structure and rice starch paste breakdown," Journal of Cereal Science, vol. 34, no. 3, pp. 279-284, 2001.

[20] A. Kesarwani, P.-Y. Chiang, and S.-S. Chen, "Distribution of phenolic compounds and antioxidative activities of rice kernel and their relationships with agronomic practice," The Scientific World Journal, vol. 2014, Article ID 620171, 6 pages, 2014.

[21] Council of Agriculture-Executive Yuan-Taiwan, "Organic agricultural product and organic agricultural processed product 
certification management regulations," 2009, http://law.coa.gov .tw/glrsnewsout/englawquery.aspx.

[22] American Association of Cereal Chemists, Approved Methods of the AACC, American Association of Cereal Chemists, St. Paul, Minn, USA, 1983.

[23] A. Kesarwani, S. S. Chen, and J. F. Lee, "Study of physical properties of japonica rice cultivars influenced by farming practices," Environment and Ecology, vol. 33, no. 1, pp. 121-125, 2015.

[24] American Association of Cereal Chemists, Approved Methods of Analysis, American AssociationAmerican Association of Cereal Chemists (AACC), Saint Paul, Minn, USA, 10th edition, 2000.

[25] B.-J. Kuo, M.-C. Hong, and F.-S. Thseng, "The relationship between the amylographic characteristics and eating quality of japonica rice in Taiwan," Plant Production Science, vol. 4, no. 2, pp. 112-117, 2001.

[26] C. S. Raina, S. Singh, A. S. Bawa, and D. C. Saxena, "A comparative study of Indian rice starches using different modification model solutions," LWT-Food Science and Technology, vol. 40, no. 5, pp. 885-892, 2007.

[27] L. Whistler and J. N. BeMiller, Carbohydrate Chemistry for Food Scientists, American Association of Cereal Chemists, St. Paul, Minn, USA, 1997.

[28] H. F. Zobel, "Gelatinization of starch and mechanical properties of starch pastes," in Starch Chemistry and Technology, R. Whistler, J. N. Bemiller, and E. F. Paschall, Eds., Academic Press, Cambridge, Mass, USA, 1984.

[29] R. J. Bryant, M. Anders, and A. M. McClung, "Effect of cultural management practices on grain quality of two rice cultivars," Cereal Chemistry, vol. 86, no. 4, pp. 405-409, 2009.

[30] Y. C. Kuo, B. D. Webb, and J. W. Stansel, "Genetic studies on amylose content and amylographic breakdown viscosity of milled rice by means of generation mean analysis," Journal of Agricultural Research of China, vol. 46, no. 2, pp. 99-115, 1997.

[31] K. A. Gravois and B. D. Webb, "Inheritance of long grain rice amylograph viscosity characteristics," Euphytica, vol. 97, no. 1, pp. 25-29, 1997.

[32] V. Tulyathan and B. Leeharatanaluk, "Changes in quality of rice (Oryza Sativa L.) CV. Khao Dawk Mali 105 during storage," Journal of Food Biochemistry, vol. 31, no. 3, pp. 415-425, 2007.

[33] G. S. Na, S. K. Lee, and S. Y. Kim, "Antioxidative effects and quality characteristics of the rice cultivated by organic farming and ordinary farming," Journal of the Korean Society of Applied Biology and Chemistry, vol. 50, no. 1, pp. 36-41, 2007. 


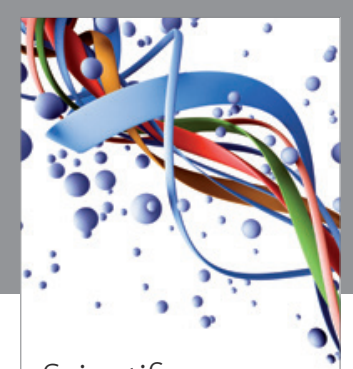

Scientifica
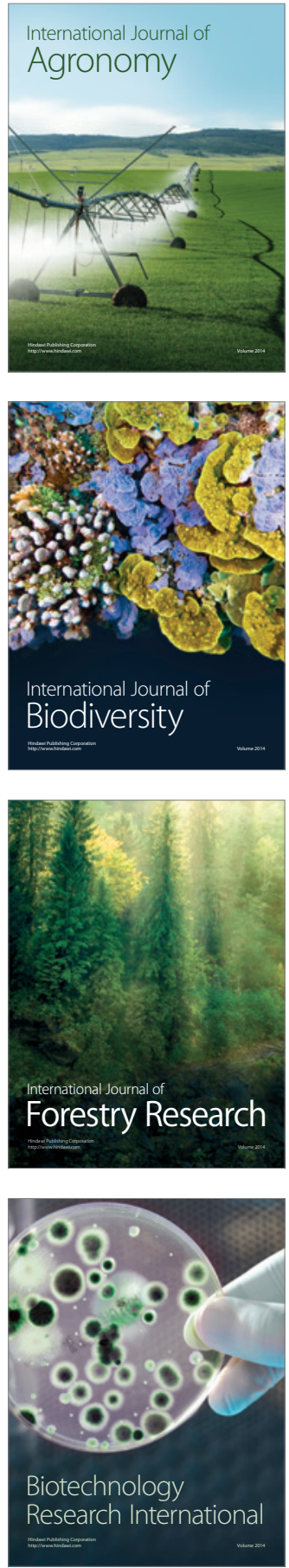
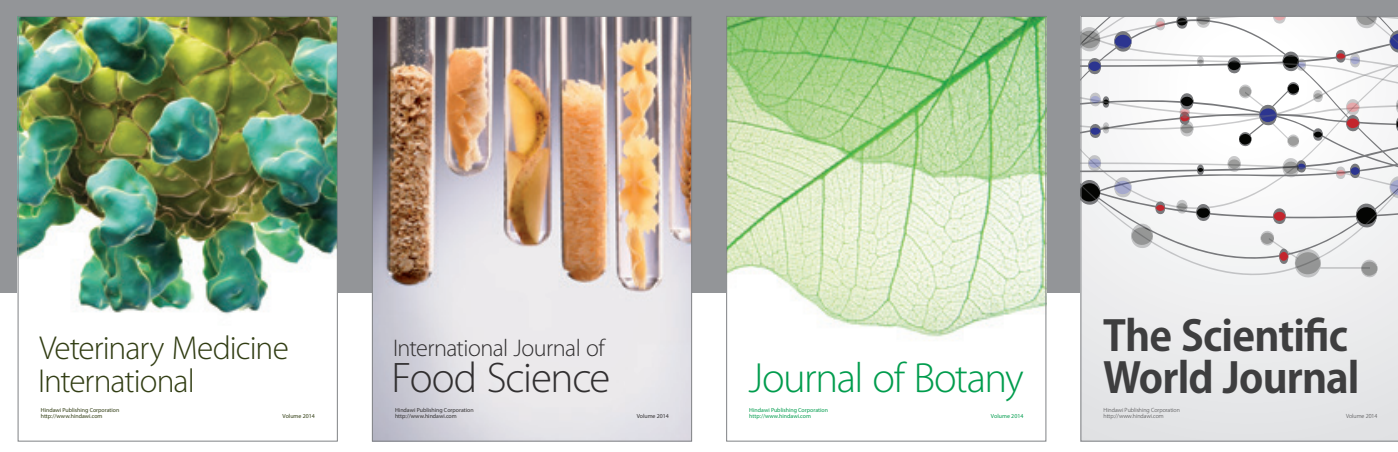

The Scientific

\section{World Journal}

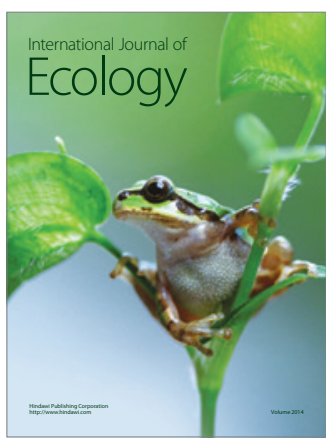

\section{Hindawi}

Submit your manuscripts at

http://www.hindawi.com
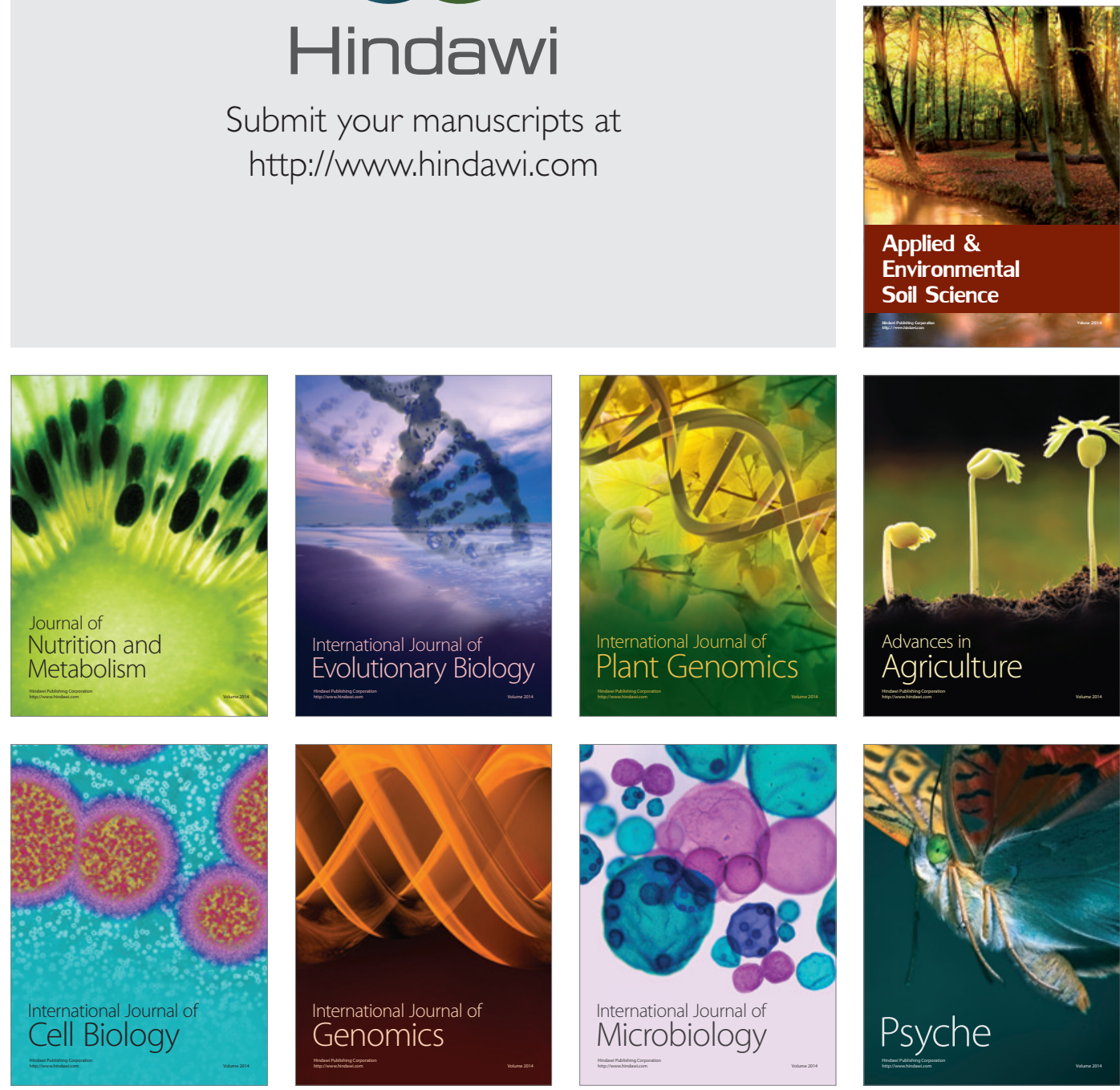
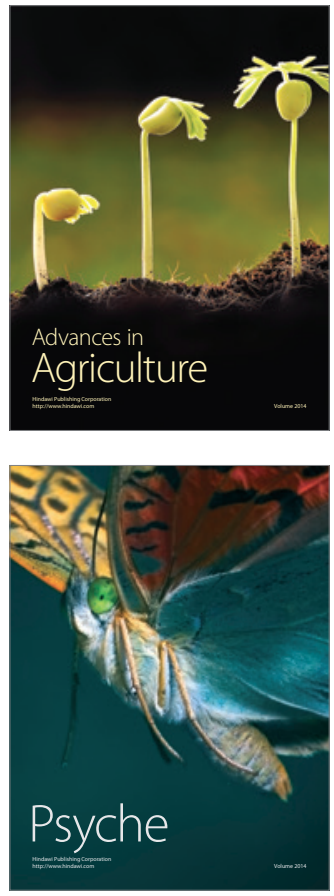